\title{
Military Doctrine Development and Curriculum Development
}

\author{
Joseph L. Walden ${ }^{1, *}$ \\ ${ }^{1}$ School of Business, University of Kansas, Lawrence, KS, USA \\ *Correspondence: School of Business, University of Kansas, Lawrence, KS, USA. E-mail: joewalden@ku.edu
}

Received: December 12, $2018 \quad$ Accepted: March 12, $2019 \quad$ Online Published: April 3, 2019

doi:10.5430/jct.v8n2p17

URL: https://doi.org/10.5430/jct.v8n2p17

\begin{abstract}
One of the complaints about the development of military doctrine over the past several decades is that "we are always preparing to fight the last war." One of the complaints that surfaced during a four year long study into the development of a common framework for supply chain management curriculum development was that the text books used in the curriculum development process were out of date. In other words, we are preparing students for the real world by teaching them about the historical business world and not the emerging business world. While this approach may work in the liberal arts such as history, it is in the words of Freire, doing a disservice to the students and not adequately preparing them for the real world. This study looks at a methodology for developing business school curriculums in particular. The study reviewed syllabi, job announcements, and textbooks for the top rated schools and for those not in the Top 25. The gap between what industry is asking for and what schools are teaching is much wider for the not-Top 25 schools than for the top ranked schools.
\end{abstract}

Keywords: curriculum development, curriculum review, written curriculum, planning

\section{Introduction}

\subsection{Introduce the Problem}

This seems to be an odd combination of topics. How is the development of Military doctrine related to the topic of curriculum development? Is there anything to learn from Military doctrine development that could be useful for curriculum reviews and curriculum development?

When I was in Combat Developments, the research and development operations for US Army forces and equipment (now known as Army Futures) and later when I was in Doctrine Development during my military career, the constant complaint that we heard from Congress was that we were continually "preparing to fight the previous war." We were accused of not looking into the future but developing concepts and doctrine that was based on the last war. After Desert Shield/Desert Storm we continued to develop equipment, concepts, units and doctrine based on the force on force battles of that conflict. As a result of the stigma of the Viet Nam Conflict, the US Army abandoned any mention of counter insurgency conflicts which came back to haunt us during the latest Gulf War (Operation Iraqi Freedom). Army Futures and Doctrine Developers are supposed to be looking well into the future and then develop units, equipment and doctrine based on the future forecasts. A recent release of the Army's Operations Doctrine produced similar criticisms (Kull, 2017) of looking at past wars rather than looking to the future.

I use this analogy of developing concepts and doctrine for the US Army based on historical experiences because it may be the same issue that we are all facing in developing current and relevant course curriculums for our students. Are we preparing the students to "fight" the historical concepts or are we looking forward to the future trends and exposing our students to what they will actually see in the real world and not what we saw or what we studied twenty or thirty years ago? While obviously history courses may not fit into this research scenario but courses in engineering, physical sciences and especially business courses fall into the criteria of this research project.

\subsection{Relevant Scholarship}

Developing a model for curriculum development is not a new topic. As early as 1971, Walker proposed a "naturalistic model" to guide curriculum development (1971). The first proposed framework for teaching supply chain management was published in 2000 when the discipline of supply chain management was still relatively new 
in academia (Johnson \& Pyke, 2000). While not a bad start, the rapid rate of change alluded to by Christopher (Christopher, 2016) would seem to indicate that a modification or revision of the framework from 2000 may be needed.

The review of literature concerning supply chain management talent and supply chain management curriculums to fill the gaps of the supply chain talent shortage reveals that while there has been a great deal written about supply chain management, there has been very little focus on the topic of supply chain management curriculum development. Jordan and Bak (2016) confirmed this in their review of 24 studies over 15-year period. Their research led them to the conclusion that there is a need for future research into supply chain management curriculums. This was confirmed by Birou, Lutz and Zsidisin (2016) who reported "There are relatively few studies which have been focused on SCM (supply chain management) curriculum" (p. 73).

\subsection{Curriculum Development}

The research that this paper is based on focused on developing supply chain management curriculums but the methodology, while not universal, can be applied to other disciplines in the business school and other academic disciplines as well.

How often are curriculums reviewed? How are new curriculums developed, reviewed and approved? Discussions were held with faculty around the country as part of a three year study into developing a common framework for teaching supply chain management. During these discussions it was discovered that a number of major institutions have not conducted a curriculum review in over ten years (Walden, 2018). Why? The answers varied from "we don't need one" to "we are happy with what we are teaching" to "we are just too busy to do a curriculum review." None of these are good excuses. We are all busy but we owe it to our students to provide current and relevant material in the classroom.

When thinking about business in general and the supply chain management field in particular, so much has changed in the past ten years that a program that is "happy" with what was being taught ten years ago is probably outdated and certainly not providing relevant knowledge and skills to prepare the students for what they will see in the real world. One particular university enthusiastically provided a "current syllabus" for use in the study. However, this syllabus showed the use of a 1995 supply chain management case study as part of the higher level supply chain course looking at supply chain and business information technology. With all of the changes in technology from 1995 to today, one would be hard pressed to defend a twenty-four year old case study as current or relevant.

Even if a curriculum was current and relevant ten years ago, the chances are very good that it is not current or relevant today. Discussion groups at major supply chain conferences around the globe addressed the need for current and relevant business and supply chain curriculums. Sessions were held at the 2015 Warehousing Education and Research Council Annual Conference (Walden, 2015), the APICS 2015 International Conference and Exposition (APICS 2015), and the 2016 Southern Africa Production and Inventory Control Society Conference. The focus of these discussion sessions was "What are we teaching and how do we develop our curriculums?" The attendees at these sessions provided a full spectrum of views from practitioners, students and educators. The consensus of all three sessions was that too many schools were using outdated topics to prepare students for their futures in the commercial world. Much like the analogy of using the last war to prepare for the next war, it would seem that many schools were looking back rather than forward in developing curriculums.

Part of the curriculum development dilemma may stem from the lag time necessary between changes and advances in business and the time necessary to write/update a textbook and get the new ideas out to academia. One senior university official that was interviewed as part of the three year study reported a 12-18 month time lag between new textbooks being released and the development and approval of a new syllabus. When you add in the time lag of writing a textbook, updating the draft manuscript, editorial review and then the final approval of the textbook, you are now looking at up to three years from new idea to new approved syllabus. As new developments such as block chain and the internet of things come along, by the time the new topics are in textbooks as emerging topics they are probably already in practice and something new is being developed. This leads to the process of trying to prepare our students using old materials and preparing them for the last conflict rather than the next business conflict.

\section{Method}

The three year study into teaching supply chain management looked at the introductory supply chain management syllabi for seventy eight schools in the US. The initial database of syllabi contained over 300 syllabi from around the globe. The data was collected through a variety of sampling means. The first sampling technique was an online 
search for "supply chain management syllabus." The second sampling technique involved a sample of convenience by reaching out to colleagues and asking for copies of their syllabi. This led to a snow ball effect sampling as some of those colleagues reached out to other colleagues and informed them of the study resulting in additional syllabi being collected. The fourth sampling technique involved contacting schools ranked in the Top 25 by Gartner Research and asking for copies of their syllabi. The final sampling technique again involved a search of data online through the website CourseHero.com. This resource provided additional syllabi for leading schools that did not respond to the data call techniques.

They syllabi were then narrowed down to introductory supply chain management courses as the first phase of the research. The narrowing methodology was accomplished through a series of reviews and cuts. The first review removed the international courses from the data base since the initial research project focused on US courses only. The second narrowing process removed all duplicate courses from the database. The third review of the syllabi removed advanced courses or narrowly focused courses to enable a focus on introductory courses only. The final review removed any of the author's courses to ensure objectivity and prevent skewing the data set and analysis findings.

The remaining syllabi were broken out by those schools that were recognized by the Gartner Research surveys as Top 25 University Programs and those schools that were not in the Gartner Top 25 University Programs. The syllabi for Top 25 programs as well as the not-Top 25 syllabi were compared with a set of 140 job announcements for entry level supply chain managers collected over a period of four months during the 2017 major college/university recruiting cycle using Careerbuilder.com, Indeed.com, Monster.com and jobsinlogistics.com. A comparison of key words from the syllabi and job announcements was based on the APICS Basics of Supply Chain Management Certification Manual (APICS-SCC, 2016) and the appearance of these key words. The comparison process looked at what terms were used in the syllabi and what key terms appeared in the job announcements. The assumption of the study was that the job announcements reflected what companies needed as far as skills and knowledge from graduates being recruited by the companies and that the key terms in the syllabi accurately reflected the concepts and topics being taught to the students in the supply chain courses.

\section{Results}

The schools that were ranked in the Top 25 had a composite match of $88.7 \%$ match between what industry says they need and what academia says that they are teaching. When the non-Top 25 programs were analyzed, the resulting match was only $41.5 \%$. This would indicate that while the best ranked schools are doing a much better job, as a whole we appear to be preparing our students for the last conflicts in business rather than the current or future conflicts that the students will see when they graduate.

How do we fix this? We have to conduct frequent and regularly scheduled curriculum reviews to ensure that what is being taught is current, relevant and future looking and not business history. Waiting ten years to conduct a curriculum review is way too long. We have to get out of our comfort zones, research what is needed for our graduates and ensure that we are providing them with the concepts and business doctrinal background to set the conditions for success for the students in the commercial world that they will be working in.

Looking specifically at the development of supply chain management curriculums, the following lessons were learned or observed during this research project:

How do you conduct a curriculum review at the college/university level? When was the last time you did one? Has your school or department ever done one? Why do some schools go so long between curriculum reviews? Excuses run from "we have never done one" to "we are happy with what we are teaching" to "why do a review?" None of these are reasons but simply excuses. Curriculum reviews should be planned, regularly scheduled and documented.

As a full time lecturer, part time lecturer, or tenure track professor why should I care about curriculum reviews? How often is enough or too much? Who should be involved? What is involved in a curriculum review and what do I do with the results? All of these are great questions that need to be answered. Also important to the development of a relevant curriculum is the need to balance academic theory with real world applications. A swing too far in either direction may skew the value of the curriculum to the students.

I worked for a major University that caters to US Military personnel teaching a couple of online courses that had the exact same material that had to be presented in the exact same way in each section of the online courses. The material appeared to have been developed by someone that had worked in operations management decades ago and the book of case studies were decades old, some of the companies did even exist anymore as a result of issues or 
decisions made long after the case studies were written. While the university kept insisting that the materials were reviewed annually during the five years that I taught for them there were no changes to the materials or case studies. What amazed me was that as a practitioner in the field and an adjunct professor for these courses, the curriculum review process never asked me what should be included in the curriculum. Some of the case studies used in this program were over twenty years old. Again begging the question of how relevant a two decades old case study is to preparing students for real world jobs.

The same was not true for their on ground courses. In those courses while the textbook was dictated, the topics discussed by the instructors were not as stringently dictated allowing for the use of current examples of the topics thus making the course more relevant for the students.

\section{Discussion}

The curriculum process for developing a supply chain management framework was predicated on work done by Johnson and Pyke on establishing a framework for teaching the relatively new discipline of supply chain management (2000). When Johnson and Pyke developed their initial framework for teaching supply chain management there was little consensus as to what supply chain management was and how it should be taught. Complicating matters was the elimination of the requirement in 2015 by the Association to Advance Collegiate Schools of Business (AACSB) to teach operations management. At the same time, there was a growth in the demand for supply chain management education based on the large shortfall of graduates to fill all the new supply chain jobs. I mention this because this accreditation change may have led to a number of schools changing their courses from operations management courses to supply chain management courses without changing the curriculum as revealed from the syllabi analysis by looking at the textbooks being utilized. The review of the syllabi showed about $25 \%$ of the non-Top 25 schools with a supply chain management course but an operations management textbook.

Of concern from the research to update Johnson and Pyke's framework for developing supply chain management curriculums revealed that a number of schools do a curriculum review every couple of years while a larger number of schools contacted have not done one in recent memory and a couple of schools having gone over ten years without a curriculum review for some of their programs. This got me to thinking that maybe some schools have gone so long without a curriculum review that there is no one left on the faculty that remembers how to conduct one or even worse, no one on the faculty has ever been involved in conducting a curriculum review.

If that is the case, maybe it is time to establish some suggestions or guidelines on conducting a curriculum review based on the three year study on the development of supply chain management curriculums and common frameworks that involved reviewing over three hundred supply chain management syllabi and discussions with supply chain faculty and supply chain professionals around the world.

The goal of this paper is to provide/establish guidelines for successfully conducting a curriculum review and at the same time provide guidelines on improving or modifying curriculums based on the results of the reviews. One of the limitations for this study is that it may not have universal applicability but should at least get course authors thinking about how to improve the curriculum review process for their subject matter.

Curriculum reviews are similar in nature to conducting Strength, Weaknesses, Opportunities, and Threats (SWOT) Analyses in corporations - both processes require extreme honesty and thick skin if the review and analysis is going to be successful. In the corporate world the SWOT looks at what the company is doing well (Strengths), what the company is not doing well but should be (Weaknesses), what opportunities are available to the company (Markets, Customers, Acquisitions), and what is keeping the company from being as successful as possible by identifying the threats.

The planning for conducting a curriculum review is very similar to the SWOT analysis or at least should be. From a curriculum review/curriculum development perspective, the critical areas to focus on are what are we covering and what is not being covered (weaknesses). Are we covering the right materials and topics? At the same time the curriculum reviewers need to consider the strengths of the current curriculum. After all there has to be something good about the curriculum even if some of it is outdated or non-value added. What are we doing well with the current curriculum that should be sustained as we update the written curriculum?

The next step in the SWOT Analysis is to look at opportunities. From a curriculum development perspective this means looking at what opportunities or additional topics should be included in the curriculum to improve the output from the process or in simpler terms, improve the quality of the graduates. The opportunities from the SWOT analysis analogy are those things that the leading schools are teaching that may not be a part of our curriculum but 
may should be included. This would also include emerging technologies or topics. The opportunities may also include what are other programs doing to help students get internships or other relevant experiences such as study abroad program?

The threats to the curriculum review process may not be external to the organization as they are in a SWOT analysis. The biggest threats discovered in this research project were actually internal. These threats were faculty members that had no desire to change their curriculum, written or otherwise, and are not properly preparing their students for success in the real world.

\section{Recommendations and Conclusions}

\subsection{Recommendations: What are the recommended steps in establishing the curriculum review?}

The first step is to remember that this is not a one person operation. Everyone involved in teaching the courses underneath the umbrella of a major or even minor program should be involved. The more people that are involved in the process the more consensus building is necessary, however, by getting all of the stakeholders involved in the curriculum process it should be easier to make change happen. The Theory of Constraints looks at three questions to improve operations. 1. What needs to be improved? 2. What do we improve it to? 3. How do we make the improvement happen? Keeping in mind that every improvement is a change but not every change is an improvement. This is important to keep in mind because we do not want to simply change the curriculum to meet the need to update it without actually making it a better course. The goal of curriculum reviews should be to improve the course and make it more relevant to the needs of industry. By getting more stake holders involved in the process, the reviews should provide improvements and buy in during the process, thus making improvements come a little easier.

The next step is to collect the syllabi for all of the courses underneath a particular major's program. This means that if there are ten courses related to a major topic then all ten syllabi should be collected and analyzed for common topics and linked topics. During this phase of the review it is critical to look for overlapping subjects. For example, during the curriculum research and analysis process it was discovered that two courses in the same program were duplicating as many as eight class periods for the same topic. Approximately one fourth of the academic year was duplicated in two of the required courses in that particular focus area. In the business world with the rapidly changing face of business and customer options for products and options for how to buy the products, duplicating one fourth of the school year may indicate that there are critical topics that may not be discussed or taught as a result of the duplication. A class period or two may be necessary overlap or duplication if the courses are sufficiently spaced that time may be necessary for review and refresher. However, one fourth of the academic semester is way beyond refresher. A similar study for the US Army a few years back revealed over forty hours of duplication between two phases of a senior level program. The result was the ability to add forty plus hours of instruction on other important topics.

The next step is to survey industry to see what the companies that are recruiting for our graduates are looking for. This could be done through a survey of companies through the school's career services centers or through a review of job announcements posted on the major recruiting websites. A recent study on developing a supply chain management common framework compared the syllabi from seventy-eight colleges and universities for their introduction to supply chain management courses to the requirements put forth in job announcements for entry level supply chain management positions as advertised over a five month period on the major job sites such as Careerbuilder.com, Monster.com, and Indeed.com. The results of this comparison revealed that there was a major disconnect between what was being taught in the introductory courses and what industry was looking for. In fact, there was only a $44 \%$ match between the syllabi topics and the job announcements topics for the non-Top 25 schools. This would indicate that most universities are not teaching current and relevant materials in their supply chain management courses. However, the Top 25 schools demonstrated an $88 \%$ match between what industry stated they needed in new supply chain graduates and what the top schools were teaching. This step may not be applicable to every discipline but certainly has applications to physical sciences, engineering, and business and may have applications in schools of education. The real question that this step answers is: "Are we teaching what the students need in order to be successful in their new careers?"

Is there a disconnect between what is being taught in the curriculum, as reflected in the syllabi, and what industries are looking for in the students that they recruit and hire? If one small company is looking for something that is not being taught that may be an anomaly, however, if many companies are asking for skills or subject knowledge that is not being taught, that would indicate a weakness in the curriculum and an opportunity to improve the program and 
curriculum.

The next step in the curriculum review process is to update the syllabi and the written curriculum. Do we have outdated materials? One review showed that an instructor was using a twenty year old case study about information technology. When you think about the leaps forward in information technology in the past twenty years, this would indicate that perhaps the material should be updated. Are there topics that are relevant in today's environment that are missing from the syllabus or program? In a recent address to a graduating class, Lou Holtz told the graduates that unless you are moving forward you are moving backwards. In other words, an old curriculum will not keep your program as a leader and may very well move you from a top ranked program to unranked or lower ranked. The same sentiment is echoed in Rick Lynch's book Adapt or Die. In that work, Lynch makes it clear that organizations - and this includes academia - have to adapt to changing requirements or will become extinct (2013). When analyzing the Top 25 supply chain programs' curriculums it was this ability to adapt to changing industry requirements that set them apart from the non-Top 25 programs.

The final step is to publish the new curriculum and start collecting data for the next review. At the same time, it is also time to start making a file for lessons learned during the curriculum review process. Collecting a file of what went well with the review and what did not go so well will help provide the next curriculum review team a head start on the process. If schools capture the lessons learned every time they conduct a review, each future review should become easier and better than the previous ones. This will also provide a continuity plan for future reviews should members of the current review team depart before the next review. The steps of the curriculum planning and review process are review process are summarized in Figure 1.

\section{Steps in a Curriculum Review}

1. Get everyone on board - this is not a one person job!

2. Collect all of the syllabi for the program being evaluated.

3. Survey industry - what are employers looking for?

4. What are the emerging trends in the industry?

5. Update the syllabi to eliminate duplication of topics.

6. Add in new and emerging topics.

7. Publish the new curriculum.

8. Capture lessons learned from the process for improving the next review.

9. Institutionalize the review process.

Figure 1. Steps in the Curriculum Review Process

\subsection{Recommendations}

In his seminal work on pedagogy and curriculum development, Freire insinuates that if our curriculum is not meeting the needs of the students and the industries that are hiring our students, then we are creating harm to the students (Freire, 1998). Conducting curriculum reviews can be painful, however, they are a necessary step in improving what is taught to students and can have a big impact on the reputation of the school and the rankings that drive applications to the school. Using the steps identified in this paper as a guideline will help you get the ball rolling towards providing current and relevant education to your students. If we are not providing the students with an education that is preparing them for success in their jobs and careers, why are we even teaching? 


\section{References}

APICS 2015. (2015). Best Practices in Teaching Supply Chain Management. Conference Proceedings. Las Vegas: APICS. APICS-SCC. (2016). CPIM. Retrieved from APICS: http://www.apics.org/docs/default-source/certification/cpim-bulletin-north-america.pdf?sfvrsn=12

Birou, L., Lutz, H., \& Zsidisin, G. (2016). Current state of the art and science: a survey of purchasing and supply chain management courses and teaching approaches. International Journal of Procurement Management, 9(1), 71-85. https://doi.org/10.1504/IJPM.2016.073388

Christopher, M. (2016). Logistics and Supply Chain Management (5th ed.). Edinburg Gate, Great Britain: Pearson/Financial Times.

Freire, P. (1998). Pedagogy of Freedom. Lanham, Maryland: Rowman \& Littlefield.

Johnson \& Pyke. (2000). A Framework for Teaching Supply Chain Management. Journal of Production and Operations Management, 9(1), 2-18. https://doi.org/10.1111/j.1937-5956.2000.tb00319.x

Johnson, M., \& Pyke, D. (2000). A framework for teaching supply chain management. Journal of Production and Operations Management, 1, 2-18. https://doi.org/10.1111/j.1937-5956.2000.tb00319.x

Jordan, C., \& Bak, O. (2016). The growing sale an scope of the supply chain: a reflection on supply chain graduate skills. Supply Chain Management: An International Journal, 21(5), 610-626. https://doi.org/10.1108/SCM-02-2016-0059

Kull, D. (2017, May). The Myopic Muddle of the Army’s Operations Doctrine. Military Review. Retrieved March 20, 20019 , from https:/www.armyupress.army.mil/Journals/Military-Review/Online-Exclusive/2017-Online-Exclusive-Articles/ Myopic-Muddle-of-Army-Ops-Doctrine/

Lynch, R., \& Dagastino, M. (2013). Adapt or Die: Battle-tested Principles for Leaders. Grand Rapids, MI: Baker Books.

Walden, J. (2015, May 29). Best Practices in Teaching Supply Chain Management. Sun City, South Africa, South Africa: South Africa Production and Inventory Control Society.

Walden, J. (2018). Teaching supply chain management: developing a common framework. National Business and Economics Society. NBES.

Walker, D. (1971). A Naturalistic Model for Curriculum Development. The School Review, 1, 51-65. https://doi.org/10.1086/443014 